\section{ORIGITAT COMTUTHCATIONS.}

\section{OBSERVATIONS ON CHOLERA.}

\section{By SAMUEL WILKS, M.D.Lond., Physician to the Surrey Dispensary.}

The following facts and remarks are gathered from my observations of the present epidemic as I have witnessed it in my neighbourhood of Southwark.

In considering, first of all, the nature of cholera, we find ourselves still in the dark respecting it, although some few facts have been brought out which tend to throw a gleam of light upon the subject. The common use of the term "cholera poison" is indicative of a theory, more or less vaguely held by the majority of the profession, that a specific agency, as the hypothetical cholerine, is the prime morer of the disease. The term is not an inappropriate one, considering all the analogies which the symptoms of the disease have with the effects of a poison. If a poison, say the powder or vapour of arsenic, were diffused through a room filled with people, its effects would be proportionate in each individual to the dose imbibed and to the peculiar power of the patient to receive or repel its agency. Thus there would be those who bad taken into their system a large dose of the poison, succumbing and dying a speedy death or narrowly escaping with their lives, and those who from less doses of the poison would be suffering all degrees of symptoms in proportion. At the same time, the individual peculiarities of persons would be showing themselves. It would be seen that not all suffered in a like degree from the same amount of deleterious material ; but that some were able in a striking manner to repel its influence, owing to their peculiar idiosyncrasy or to some temporary cause. Some theories of the cholera poison cannot admit any difference of degree in its quantity and power ; for the cholerine being likened to other animal poisons, as small-pox, it must be looked upon as single and indirisible, and always equal in intensity. The vaccine, for example, is a peculiar animal principle, supposed to be as definite in its composition and qualities as any chemical substance. With such a view, the difference of degree of symptoms in persons inoculated by it, or the fact of some escaping altogether, must be put down entirely to the individual susceptibility. The peculiar recipient power of the patient is the most importaut point with those who hold the above-mentioned doctrine. Some views, howerer, must allow various degrees and amounts of poison. If the latter be allied to the miasm which produces intermittent ferer, and be of a vegetable nature, then various amounts of its quantity and virulence may certainly be allowed to exist, as the poisonous activity of marsh miasmata is well known to differ in various places and times. Even Dr. Snow's theory, and others which refer to some definite vegetable and animal agency must admit the same: for supposing the smallest amount of fungus to be capable of reproducing itself and of causing the symptoms attributable to cholera, yet the organic nucleus, in passing in to the body, must have a greater chance of being destroyed than if several had entered, and therefore practically, the larger the dose the patient receives the greater the chance of his being the subject of cholera or other malady. Those persons, however, who look upon the constitution of the patient as the main element in the production of the disease after the imbibition of the poison, hold practically very different notions of the disease from those who maintain such a doctrine as Dr. Snow's, although even the believers in specific agencies allow that a difference in the effects produced is attributable to the peculiar idiosyncracy of the patient. Both parties admit a poison; with one, the discovery of its introd"stion into the system is most important; with the other, the peculiar receptive power of the individual is paramount. A theory which can suit the majority of medical men must be one which would include both opinions, and would be something as follows. That a peculiar poison, say cholerine, exists, which in some instances may be 80 powerful that, if taken into the system, it otrike down the most healthy, and in other cases may bo 80 weak that it produces only a shadow of symptoms; and on the other hand, that certain conditions of constitution are 80 predisposed to this peculiar agency that they at once succumb to its influence, while other constitutions from some hidden cause are so repugnant to it that they altogether escape with impunity. Although, as I before said, the extremes of this theory are almost opposed, yet I believe that the majority of medical men hold them, vaguely enough no doubt, since they will be found speaking of the cause of cholera as specific, and at the same time of the condition of the recipient individual as highly important. So difficult is it to obtain any general rules with respect to this disease (although our daily journals inform us that the laws of cholera are well known), that instances which tend to show both its specific influence and those which show the highly operative effects of the predisposition of the patient may both be brought forward. Everyoue has seen instances of patients being struck with death (to use a popular phrase) who shortly before were in good health, and in whom there was at no time any amount of those symptoms which seem in other cases to tend principally towards the fatal result; and on the other hand, he must have seen patients who had premonitory symptoms of the disease for days and days, and who seemed as it were soliciting it, and yet the attack has been so long protracted.

With regard to the predisposition to cholera, as yet only certain symptoms have been considered as indicative of this condition; and these are they which resemble the symptoms of the disease itself, I mean diarrhoea. If, howerer, a predisposition be always necessary to the production of cholera, other conditions of system must be present than those affceting the stomach and bowels; for often, as in such sercre cases as I hare mentioned, the poison has begun its work, and shrunken and collapsed its victim even before any rery great derangement of these organs has been obserred. Finch cases tend to show either that the poison once introduced will assuredly destroy its recipient, or they shew that, if a predisposition exist, it is quite inperceptible to us, and unknown to the feelings of the patient. Among examples of such cascs I can call to mind three persons, whom I was in the habit of seeing daily prior to the attack. One was a strong healthy-looking hoy, who was struck down and died in a few hours; a second was a nurse, who was quite well and engaged in her duties until twenty-four hours before death, when she was suddenly seized with cramps, took to her bed and was soon collapsed; the third was a woman, who was daily in the habit of visiting me on the part of a friend who was a patient of mine, and who always appeared in good health, and yet was suddenly seized in a similar way to the other cases and as shortly diel. In these cases there were no premonitory symptoms, and the patients appeared in robust health shortly prior to the attack. I have seen a considerable number of other cases where a similar history has been giren me.

If diarrhen do occur as a premonitory symptom, it is looked upon in two lights, either as predisposing to an attack of cholera, or as an evidence of the iucipient working of the poison. I think there are not many who now bold a third view, and say that such diarrhea would of itsclf lead on to cholcra-that the one was the mere derolopment of the other. Such a view, as far as my knowledge of the opinions of medical men is concerned, is now exploded, though formenty held by many. The connexion of the ordinary diarrhoed with malignant cholcra cannot be overlooked. The fact of the great prevalence of the former in London during the past autumn, during the raging of the sererer eridemic, must bo important. Those who delight to dwell upon the specific cholera agents attempt to explain away its existence by making it apparent only, and dependent on quite secon lary causes, such as the fear of the epidemic to which every one has been subject, the especial observance which erery one took of the state of his stomach and bowels, and the direct fact that a large number cf cases were noted by the house to house visitors. Allowing all these causes to hare 
bern in operation, they can only in a very small degree sincoch an explanation of the diarrhoes epidemic. At the Eprrey Dispensary, from which I gather most of my experience, the poor have applied daily by hundreds for medicine to stop looseness of the bowels; and among my more regular patients at that establishment who were the subjects of rarious maladies, diarrhoea during the months of August and September was the principal symptom complained of; which, indeed, superseded all other complaints. The remedies for phthisis, chlorosis, and such ordinary diseases, had to be entirely foregone for diarrhoea medicine; and in very many cases, as often as this was discontinued, the bowel symptoms returned. In fact, a great many patients have had so many attacks, that they may be said to have been subject to diarrhœa for four or six weeks. I never remember to have seen anything like the amount of diarrhoea which has existed during the past autumn; and not only a disposition to diarrhoea has been observed, but a general gastric disturbance, marked by indigestion, flatulence, colicky and spasmodic abdominal pains. Such symptoms, also, have followed those who have had an attack of diarrhoea, for days or weeks afterwards. This has been the experience gathered in this neighbourhood, and probably has been the same elsewhere.

The fact of the co-existence of diarrhoa with cholera is, then, of great and striking importance; and, in the first epidemic which prevailed in London, it was the cause at once of a close convexion being established between them. The prevaleuce, however, of the malignant cholera in northern towns, and other places, where no such tendency to diarrhoa existed, has quite nullified this opinion. On the other hand, this being now the third time when the malignant cholera has co-existed with the English form in this metropolis, besides as in last year slight outbreaks in the autumn, we cannot but ask what connexion exists between them. Hare the same causes which have always produced the autumnal diarrhoa been present this year in a more powerful form? or has the malignant cholera had any share, by its poisonous influence, in producing the affection in question? The latter is a theory we are hardly willing to allow, and yet cannot altogether get rid of. The effects of cholera are so marked and so rapid, that it is difficult to imagine the same poison producing such lesser effects, as seen in the ordinary diarrhcea; and, as before said, the analogies of other animal poisons are opposed to this notion of degrees of action of the same principle. $\Lambda$ lso, if a specific agency be allowed, and at the same time various shades of its virulence, its potency must in many cases be all but nullified. Still, one cannot be blind to the fact that a number of symptoms have existed in patients, which seem to be referrible only to a choleraic influence. Many of the gastric and intestinal complaints we bave lately seen, resemble cholera symptoms in a mild degree; and, what is remarkable, the existence of cramps or spasm of the miscles, which is often such a horrible feature of the cholera, has been constantly complaincd of in patients otherwise healthy, and which makes it appear as if a common influence was instrumental in producing both. Not only cramps, but more marked symptoms of cholera, have been very frequent during the epidenic. Persons have been seized with a looseness of the bowels, which has readily passed off, as at other times; but there has accompanied the malady a depression and coldness, or approach to collapse, quite peculiar. Although it is dificult to get rid of these facts, yet I cannot imagine that the diarrhoa, of which I have witnessed so much, could have been produced by any such peculiar influence, because the majority of cases were simple in their character; many continued better and worse for weeks together, and never went into cholera. These negative facts are remarkable, and worthy of notice, that in districts where cholera was raging, patients had been residing, who for weeks and weeks had been the subject of diarrhoea, and jet escaped this direful disease. It can hardly be imagined that such diarrhoa was due to a specific cause, and yet, although exlsking that long time, never dẹceloped itself into the true form.
What inference, then, do wo dran from tho fact of eholece and dinrrhoes existing together? Perhaps the mfeot would be, that the ordinary causes producing our autumn diarrhoee were this year peculiarly potent, and that the same causes predisposed to cholerw in the maligmant or specific form; leaving out of the question whether diarrhoen, or its tendency, must have existed to indicate the predisposition in individual cases. It might be here remarked, that the plague and sweating sickness both prevailed in London at this same season; which looks as if our autumn was particularly favourable to the breaking out of any epidemic disease. Many theories have been framed, which endeavour to show this connexion between diarrhoes and cholera; but none have been quite successful. That their co-existence is a mere coincidence is the opinion of those who point to the prevalence of cholera in other countries, where there is not found any prevailing constitution of the season to produce diarrhca ; and this I suppose is the opinion of those also who hold the doctrine of a specific agency, as a fungus or cholera secretion, as necessary for its development. The occurrence of cholera in any individual, according to such theory, is a mere chance, according to the water he drinks or the air he breathes; and therefore how the prevalence of an epidemic diarrhoea is related to this, remains to be shown by the advocates of the theory. I believe most persons hold vaguely an opinion that the causes (such as heat of weather, etc.) which generally produce our English diarrhca, were this year peculiarly rife; and that these same causes were highly instrumental in predisposing to attacks of cholera, whose poison was floating about seeking for its suitable nidus. I must, however, again state that many cases of diarrhoea had symptoms so approaching to the severe form of cholera, that the same agency must have produced both.

With reference to the frequency and importance of premonitory diarrhœa; although diarrhœa has existed so universally, it cannot by any means be said to be a constant forerunner of cholera. During the height of the epidemic, it certainly was absent in a large number of cases which $I$ witnessed; and coupled with this is the negative fact that, in notorious cholera districts, many unhealthy persons, the subjects of repeated or chronic diarrhoea, have altogether escaped. The apparently healthy were as often attacked as these. During the carly part of the epidemic, this premonitory diarrhoea no doubt was often present; but not so universally as some have stated, and certainly not as a rule, as has been put forth by the public press. The opinion no doubt has been promulgated for prudential reasons, and to quiet the public mind, by showing how, if taken early, the disease would succumb to efficient remedies.

With respect to any other predisposing causes besides that of diarrhœa, thinking an opportunity was offered by the occurrence of cases in a large hospital, to discover what conditions were farourable to its development, I anxiously watched the cases in Guy's, in order if possible to arrive at some result upon the question. I may state that, in all the wards, patients have been occasionally seized with the prevailing disorder; and, most remarkably, the first few that occurred were among three classes of disorders, viz. typhoid fever, rheumatism, and phthisis. The seizure of the disease upon cases of typhoid and phthisis did certainly seem to corroboratc the view of the determining cause of it being in the alimentary canal; as in all the cases attacked diarrhœa and bowel irritation had existed. It was also remarkable that during last October, when cholera prevailed slightly in this district, of a few cases which were attacked in the hospital, the majority should have been of the same diseases as mentioned above. I have also seen in private both a case of rheumatism and two of typhoid fever attacked with cholera.

A further experience, however, showed that no class of disease was proof against its assaults; and that patients with maladies of all kinds equally suffered-those very ill, those convalescent, and others with surgical diseases, whose internal viscera were all sound. An opportunity also occurred to consider the question of contagion and cause of 
she divenea. Individual cases in all parts of the hospital, cocurred in the large wands and in the detached apertments -in those who had recently entered the building, and in those who had boen inmates for months. Although always coming in contact with the medical officers, nothing like direct contagion was apparent; and, as regards the introduction of the poison of cholerine by the food or drink, this could never be discovered. Some of the patients had drank water: but others, as those with fevers, who were fed by the nurses, had had no simple water; all their nourishment had been cooked or boiled, and no such neans of introduction appeared possible. I must confess that, after all these investigations, I am still quite in the dark as to the cause of the attack in these cases. This was hardly what I expected, with such favourable opportunities for research into the subject. The first case attacked last year in the hospital was that of a girl with incipient phthisis, who lay at the extreme end of a large ward, who had had no visit from her friends for several days, who kept her bed, and whose physician and other attendants had had as yet no contact with any cholera case.

As regards the question of contagion, my experience does not afford me one case at all bearing upon the subject. I have, however, the negative facts in abundance of cases occurring where there appeared no possibility of contact with any previously diseased person. I may also add, that at Guy's Hospital only one nurse has died; and this occurred at the close of the epidemic, and when only two convalescents remained in the wards. For nearly two months the two cholera wards were full, and the nurses escaped with impunity.

Difficult as it is to bring the origin of cholera home to one definite cause, yet, as we have seen, there are numerous agencies which seem to bear upon the question of its nature and prevalence; and the difficulty is not lessened by some of these being apparently contradictory, or having no connexion with each other. The preference for low districts has been well established; and this south side of the river has this year kept up its character for favouring the progress of the epidemic. Nearly half of all the cases in London have occurred on the southern side of the river; and it must be remembered that some parts of this district are several feet below the high water mark of the Thames. Localitics have been attacked which were considered salubrious; and the neighbourhoods of Camberwell, Brixton, and Clapham, have shown numerous victims; while many parts of the city and crowded east districts have escaped.

The state of the weather and season has varied so much in the different countries and cities attacked with cholera, that their influence has been regarded as nil; and yet, in London and elsewhere, they seem to have a marked connexion with the virulence and intensity of this plague. As it prevails elsewhere in the winter time, but in London during the autumn, and ceases on the approach of cold weather, it may be that it merely runs a course cocval with the ordinary diarrhcea; and if this be 80 , it shows still further the connexion between them. It has been observed, however, in a marked manner, in this neighbourhood, that the number of persons attacked has preponderated with a rise of temperature, and again has diminished with a reduction of heat; and the continuance of the cholera up almost to the present time, seems connected with a similar factthe unusual warmth of the season. It was hoped that the present epidemic would stay its ravages after the first week of September, following the rule of former years; but this has not been the case : and, in connexion with this fact, it must be remembered that the month has been unusually hot. Even the commencement of the present month (October) was warm in an unprecedented manner: and at the same time the cholera continued its ravages, though less severely ; that is, the numbers attacked were fewer, though the seizures were often as violent and sudden as ever. It must be observed that, at the beginning of September, the diminished number of deaths in the bills of mortality was due principally to the subsidence of a temporary outbreak in the weatern district; while on our side the mortality, though less, was still very high. The state of the wind during this period has been variable, and therefore shows no connexion with the spread of the epidemic. During August it was mostly from the east, and at the beginning of September was the west, while the cholera was still raging; and, in the west it mostly remained during its subsidence.

The connexion of the weather or temperature with the virulence of cholera was well shown in Paris during the epidemic of 1849 . Being in that city during this period, I well remember the extreme heat of the weather, and the dreadful ravages of this modern plague. On the 5 th of June, Fahrenheit's thermometer was $90^{\circ}$; and the temperature of many of the hospital wards at early morning was abore $70^{\circ}$. The heat continued excessive until the 8th, when a most violent thuuderstorm broke over the city. The following day was comparatively cool; and, during the next two days, the thermometer fell to $55^{\circ}$. With this sudden change in the weather, there was an equally marked change in the numbers attacked with the prevailing disease. The days of lowest temperature and lowest mortality do not accurately correspond; but this makes the connexion of the two more striking, as the deaths registered on one particular day are often of persons who had been attacked a day or two previously. On the 8 th, 9th, and 10th of June, the deaths were between 700 and 800 daily; and it was usual to see twenty or thirty new cases every morning in the sereral hospitals. On the 11th, the mortality was much less; and in three days it fell to 300 , or not one half of the number of what it was a week previously. The sudden rise and fall of the deaths in Paris during this season was very remarkable, and particularly as associated with as sudden a change in the weather. The mortality had been rising together with the temperature throughout the months of May and June, until the number of deaths was fearful and the heat unbearable, when the storm broke over the city. The weather was suddenly changed; and at the same time the epidemic began to disappear. The occurrence of these striking events together must have been more than a coincidence; but whether connected with any electrical state of atmosphere and production of ozone, or more intimately associated with a fall of temperature, is difficult to say. The latter, I believe, was largely connected with the truth, as the decreased sickness with a cooler atmosphere has been observed in London without the intervention of a thunderstorm; and, as regards the influence of ozone, this would be difficult to prove, as during cholera or any other time its existence cannot be shown, at least in this my neighbourhood. With reference to the Paris epidemic, it should be stated that after the storm the temperature again rose, but the disease never increased; it was apparently crushed. The wind during all this pcriod, as in London, was variable.

When speaking of the predisposing causes of cholera, I intended to allude to this high mortality in Paris. The deaths were more than double what they have ever been in one day in London, during that or the present epidenic, although the population is so much less in the French metropolis than ours. This has been accounted for by the greater tendency to looseness of the bowels among our neighbours, and thus the preaisposition to cholera. If this constitute a predisposition, it no doubt is one of the real causes; for the peculiar diet of the French, owing to the large amount of soft vegetables they eat, and well cooked meat, tends certainly to produce a laxity of the bowels. There cannot be a doubt that there must be a great difference between a man who spends his life gaily and takes an hour to eat a variety of well cooked dishes, and another who is sitting all day long at his desk, and who has only an interval of a quarter of an hour to swallow ravenously a pound of half cooked meat. I beliere I am correct in saying that those complaints which constitute a curse to the life of many Londoners, are almost unknown in Paris. I allude to those stomach and bowel derangements connected with a sedentary life and a large consumption of animal diet-dyspepsia, constipation, hæmorrhoids-which are, I believe, comparatively rare with the French; conditions, 
lis, no doubt partly avoided by the means always at hand to relieve nature's calle.

With regand to the features themselves of the cholem, these are 80 well known that I shall not dwell upon them. I may remark, that as heretofore the cases were less cevere I may remark, that as and at the close of the epidemic, and at these times, even if fatal, were of a more lingering nature than during its height. In tho first two weeks, the greater number of fatal cases I witnessed died upon the thind or fourth day of the seizure. The collapse was slow in coming on, and when perfected was continued to the close of the cases; sometimes, indeed, a slight reaction might appear, but this was soon followed by a second depression and death-like coldness, and life dwindled away imperceptibly. Throughout the whole period of the epidemic I have seen many die in this way. They have not sunk in the first collapse, and they have not gone on to the secondary fever; but the depression has continued with or without the romiting and purging for three or four days, and then they have died. I have been in the habit in consequence of noting deaths from acute cholera, chronic cholera, and secondary fever. Among the peculiarities of symptoms, I have not observed the great blueness of the skin which was o remarkable in former epidemics: the congestion has been great, and the skin very dark, but the peculiar purple hue was only in some cases very apparent; in most cases livid dusky hue was present rather than a blueness. Its absence, too, I also observed in the tongue, which, instead of presenting the blue appearance of bronchitis, was covered with a creamy fur. This white furred tongue has been very gencral in cholera patients.

The most rapidly fatal case which I have seen, was one which terminated fatally, without any premonitory symptoms, in twelve hours. The great and sudden depression in such instances as these is very remarkable. Within an hour or two after the onset of the symptoms collapse has occurred; and often when the appearance of the patient does not betoken any great exhaustion, the -medical man is surprised to find the pulse hardly perceptible. The rapid tendency to cessation of all the bodily functions, looks as if the cholera poison at once struck death to the organic system of nerves. That much of the depression is often owing to the loss of fluid by the stomach and bowels, is clear from the marked reaction produced by the injection of a saline liquid into the veins. In two out of the three cases which I have seen injected this year, the reaction from the collapsed state was very extraordinarily shown by a recovery from apparent unconsciousness, a newly acquired ability to speak, and a reproduction of pulse and temperature. I may remark, that in some fatal cases the evacuations were not entirely destitute of bile, and in three or four cases I have seen blood mixed with both the stomach and bowel evacuations. With reference to the secondary fever, I have not observed that this has been more inclined to follow one mode of trentment than another: but, in a certain proportion of cases, may be expected to occur. The cause of this condition is not altogether clear. It has been thought by some that the original poison is productive of this state, and that the fever is a part of the disease. The disease has thus been likened to other fevers where various stages of the complaint are observed, and therefore, as in arue, cases are recorded where death has occurred in the cold stage; so in cholera, where the poisonous miasm is more powerful, death at this stage constitutes the rule. If the patient survive this period, the fever necessarily follows. I think this theory is hardly tenable, when we see cases recover at once and perfectly from the first stage of depression: for every one must now and then have scen patients apparently in irreparable collapse speedily recover, and in a day or two walking about quite well. Such cases are, however, the exceptions; for as a rule a slight febrile reaction sets in, as though there was a disposition to the secondary fever. If the theory will be maintained, the catting short the disease without the usual ulterior symptoms would be said not to militate against it, as the same probably is somotimes dome in forer and ague. The most ronernlly receired opinion for the canse of the necondary fever of cholem is that it is the concequence of the reaction of all the organs after the sluggish condition in which they have been placed during the collapsed stage: and this, I think, seems to be the most reasonable cause. If it bo true, one organ may be supposed to participate in the condition as well as another. Owing, howerer, to the facility of watching the urinary secretion, this has been particularly noticed, and its total cessation is found not to be infrequent during this stage. . That this, however, is not the only cause of the ferer is clear, from the fact that in many cases the secretion has been abundant; and, on the other hand, it has often been suppressed with véry few symptoms. Notwithstanding these exceptional cases, the suppression of urine has, I believe, much to do with the production of the cholera ferer. In some cases all the production of the cholera ferer. In some cases all the cases which I have lately seen in private practice, a cessation of the function of the kidney was the first thing which suggested itself. The symptoms were those exactly as found in the chronic degencration of the kidney: a semicomatose state, from which the patient could be temporarily roused, but into which he again rapidly sunk; a contracted pupil; a peculiar deep, sonorous, and sighing respiration; brown furred tongue; hot skin; occasional romiting, etc. In each of these cases no urine had been passed for three days, and there was none in the bladder; clearly all the symptoms were referrible to this fact, which was in itself an efficient cause. The romiting which occurred had, I believe, no reference to the original malady, but had its cause in the uræmic condition of the blood, as is observed in other cases of suppression. I believe that, in all cases of secondary fever after cholera, the state of the kidney has much to do with the symptoms, although it is only reasonable to suppose that a similarly congested state of other organs may assist in their production. This leares out of the question whether or not the condition of the blood is the primum nobile as in other ferers, and the organs only secondarily implicated. The discovery of bile in the evacuations after the collapsed stage would not at once show that the liver had regained its free action, for this appearance might arise from the emptying of the previously distended gall-bladder; indeed, the congested or almost pneumonic condition of the lungs confirms the sluggishness. of all the organs; and that the ferer should be produced by the retardation of the function of many important viscera is not unreasonable. The cholera exanthem, which Dr. Babington described in 1832 (see Medical Gazette), is not a very common symptom of the secondary fever, judging at least from my own experience, for out of about two hundred genuine cases of cholera which I have lately seen, I have only witnessed the eruption in four or perhaps in five cases. It cannot, therefore, be very frequent. In those in whom it occurred the treatment had been various, the patients were in a state of consecutive ferer, and the eruption appeared in full after a few hours of its first indication. When once out it remained for several days, and in two patients complete desquamation of the cuticle occurred, as in scarlatina. The eruption appears as red raised blotches, especially on the face and arms, is of an urticarious or roseolous character, and commonly has the name of urticaria febrilis. The eruption, I believe, is $82, i$ generis.

In considering the prognosis in a severe case of cholera, it is astonishing to find so many opinions held as to the relative value or importance of symptoms. Thus some practitioners like to see romiting, and endeavour to encourage it; others look upon spasms as most unfarourable, and so on. I believe myself that the only important indication is the general condition of the patient, told by his depression and pulse. A patient with not much romiting must be in a better state than one who has much, cateris paribus; and, on the other hand, the latter patient must be more farourably situated than he who is in such a state of collapse, that the stomach is already dead, and refuses to act. As regards eramps, there axe some who lool upos 
Thir prenence in mont unferoumble lisht; but my expeFience would not leed me to entertain this view. Many of the worst cases no doubt have spasms; but, on the other Iand, I have seen numerous instances in which patients have recovered where these symptoms were very violent. As another instance of showing the opposite views maintained, on the same day I heard an opinion expressed that hiccup in the consecutive fever was a favourable symptom, and soon afterwards that it was invariably a fatal one. My own experience proves neither of these opinions to be true.

With reference to the treatment of cholera, which is really the most important subject in connection with the disease, I have not much to offer, except as to the utter inability of most of the usual remedies, so that my experience at present amounts $t_{0}$ this-that the most scientific plan is to do nothing. The first thing which suggested itself to those who had for the first time seen a patient in a statc of collapse, was to endeavour to restore him by means of stimulants. The attemṕt was soon found to be unsuccessful, and the practice was at once discontinued by experienced men. We do, howerer, occasionally meet with practitioners who cannot yet remove from their minds what appeared to be a rational plan of treatment, and they still administer stimulants. The only adrantage of the plan with which I am acquainted is, that it appeals to the common sense of the public (which is synonymous with their ignorance), and gains the doctor much éclat by his persevering attempts to recover the patient. The greatest credit I have seen a medical man gain, was in a case, the first he had seen of cholera, where he incessantly poured in brandy to his patient, applied hot bottles and flannels, and had relays of attendants to unremittingly rub the limbs. The friends were satisfied that everything had been done, and I myself was as convinced that the poor collapsed patient, with his life ebbing fast, had every chance taken away, and his end shortened by such violent means, -opposed to all cxperience, and repugnant to scientific reasoning. In speaking of rubbing the limbs to remore the spasms, the plan no doubt is useful, but I have found the application of wet cloths to the part more useful. Here again, however, the doctor will have to encounter the prejudice of the attendants, and therefore if he adopt such means he had better employ a medicated lotion.

The calomel treatment I have seen largely used at former periods of the epidemic without success, and therefore was unwilling to employ it in my own patients. I have, however, witnessed its exhibition in about a dozen cases of other practitioners, and the success has been slightly greater than by other means. In the most extreme cases, the remedy was quite useless, apparently quite inert, and of which the following is an example. A middle-aged woman was seized early in the morning (by far the most usual time of the day in iny experience for a cholera attack), and was seen immediately afterwards. Five grains of calomel. were administered, and continued without intermission every quarter of an hour until half an hour before death, which took place just twelve hours after the seizure. Not the slightest effect appeared to result from its adminis tration; and the same was the case in all the other extreme instances. The principal case, where the greatest good was supposed to have resulted from this remedy, was that of a man who had had diarrhoa for three days, when the characteristic evacuations of cholera occurred, and approaching collapse. Calomel was then giren in grain doses every quarter of an hour. The pulse was perceptible, though small; the hands cool and clammy; and the voice whispering; and therefore the patient was not in extremis. After a few doses of the calomel, recovery commenced, and coincidently with this bile appeared in the evacuations. How far the treatment and result stood in the relation of cause and effect, I cannot say. The other cases where recovery took place were those of patients who had decided cholera, but were not in the very extremity of the disease. Those practitioners with whom I am acquainted, and who are staunch adrocates of the calomel treatment, confess that, in the severest forms of cholera, where collapse is rapid and perfect, their remedy is quite inefficacious : a cure is only to be obtained by its carly administration. The number of cases in which I have this year seen the treatment is too small to venture an opinion on the matter; but the result has been, that the very severe cases all died, and that the less severe ones recovered. Where such shades of difference exist in disease, it is difficult to draw a comparison between cases, and therefore it is very hazardous to give an opinion as to relative treatment. As far as I could fairly judge, however, there was a slight balance in favour of those cases who had had the caiomel treatment. The number, however, as I say, was so small that I attach no importance to the result, as the addition of one or two other cases might have made it altogether different.

The saline plan I have seen most extensively used, but with no results that can warrant any conclusion as to its supcrior efficicy over the let alone treatment. It bas been the favourite plan at Guy's Hospital, in various forms, but with the usual percentage of deaths. It has been far superior, no doubt, to the stimulant and many other injurious plans of treatment. I have seen many patients with practitioners whom I have found enjoying the same opinion as myself ; that is, a want of faith in any specific remedy; and, accordingly, none bcing administered, the hope of recovery has been equally great as when abundance of physic was poured in. My best advice has been, in a case of utter collapse and failure of pulse, to let the patient be quiet, administer nourishment occasionally by the spoonful, to keep him alive; and, if a medicine must be given, to let it be a saline, as the most rational. In early cases, of course, a more active plan is indicated, and particular symptoms of a less kind may be combated in any stage. A variety of other plans I have seen adopted, but all with a like result. I hare seen tho sulphuric acid treatment to be quite inefficacious; the hydropathic plan also, and a number of other means, such as strychnia, nitrous acid, iron, zinc, camphor, etc. The vast difference of the success of remedies, in the hands of different practitioners, is clearly due to the non-similarity of the cases they have had to treat. I have been a witness myself to the fact of a medical man boasting of his successes by the sulphuric acid plan, when he afterwards admitted that no case had been so bad as the one which we were then visiting, which was that of a patient in a state of collapse, and who died under his treatment. The only hospital where a very successful issue came of the cholera was St. Thomas's; but as here, as elsewhere, every physician had his own plan of treatment, I ain at a loss to know to what means that success was to be attributed.

With respect to the treatment of premonitory diarrhœa, if it exist. I much prefer the older remedies, and particularly opium. No doubt many cases of diarrhœe, which are stopped by such means, are of a sinple character; and that many cases of true cholera derelop themselves in spite of all treatment. Notwithstanding this, I have seen numerous instances of true cholera, accompanicd by rice-water cvacuations and great depression, checked by large doses of opium. It is indeed the remedy in which I have most faith. I have nothing to say against mauy if the ordinary astringent remedies; and, so far as sulphuric acid is concerned, I have found it very useful in the common diarrhoca. The theory which is adrocated by some, of the symptoms of cholers being indicative of an attempt to eliminate a poison from the system, secms not agrecable with the fact that many cases are cured by at once arresting these discharges. Such a theory must look upon opium, and all such remedies which tend to check the evacuations, as injurious; and those like castor oil or croton oil the only rational ones. As all $\dot{a}$ priori reasoning is of little value in the present state of our medical art, such theories are worthless; or, if this method of argument be allowed, to stop the discharge appears to be a view equally rational with that of encouraging it. Observations aud facts are what are required in this unknown region of medicine; and therefore what I simply state is, that cases of cholera, or disease which I 
conld not diatinguish from it, have been arrosted by opium and other remedies. If the eliminative theory be true, ench cases could not hare been cholera, or they must hare been of such a mild form that they would never have terminnted in that disease. If the latter be the case, even if actringents did no good, aperients must have been rery harmful, as exciting a fresh action in the bowels when the natural one was stopped. I think it may very fairly be allowed that many cases would have terminated favourably b) themselves; and the fact of ordinary diarrhoen doing so has no doubt given rise to this theory of cholera. If an offending substance has been receired into the stomach, and produces an irritation of the bowels, a dose of castor oil or rhubarb is the popular remedy to remove it; and this is generally administered with a good result; and, even without medicine, nature will generally accomplish the same ohject.

I have made many post mortem examinations of cases of cholera, and have found the appearances very uniform; but these, I am sorry to add, have not yet thrown much light upon the pathology of the disease. It would have been highly important, however, to have inspected all the bodies of those who had died in any one establishment, in order to discover the proportion between the numbers of healthy who had been attacked and those who had suffered from previous maladies. I have seen several instances where diseased viscera were unexpectedly found in persons dead of cholera ; as ulcerated intestines and degenerated kidneys. Both these morbid conditions, if not predisposing to the epidemic influence, yet must have affected much the chances of recorery. In the cases of rapid death from cholcra, the appearances of the viscera are much alike: often lividity of the skin: rigor mortis present as in other diseases. The lungs are generally found congested, and the posterior lobes often almost in a condition to be called inflamed. The heart contains clots as in other cases; and these are firm, and sometimes decolorised. The pitchy condition of the blood, I inagine, is spoken of by those who have attempted to bleed their patients during life, and is a state they theoretically consider ought to exist after the loss of so much salin. fluid. It is a fact, however, that the heart in cholera contains generally, as far as I have observed, well-formed fibrinous clots. The gall-bladder is always distended with bile; but the liver itself, as far as I can ascertain, is healthy.

The appearance of the alimentary canal is peculiar, and almost characteristic of the disease. The intestines lic coiled up in a very small space. Instead of being full of air, and having a disposition to uncoil or separate themselves, they lie in a compact mass, as seen on opening the abdomen of a rabbit, and as if they had lost their elasticity, one part receiving the impression and shape of another. They are contracted, and feel doughy to the touch, and can be moulded into any form. Their colour, as they lie in the abdomen, is peculiar; the peritoneum being of a rosy pink hue, and from its surface exudes a tenacious mucoid secretion. This latter condition, I think, is not generally described; but this may be owing to its not always being present. The appearance, however, is not uncommon, and is noticed by separnting two coils of the bowel, when a viscid mucoid string is formed between them. The secretion is hardly like that of recent inflammation, as the exudation is more like mucus, and is sticky, than the greasy sero-albuminous fluid of ordinary inflammation. The internal mucous surface of the intestines has been often described, the sodden state of the whole membrane, and the loss in many parts of the epithelium. The white creamy secretion covering its whole surface, mixcd with a large amount of fluid, forms the ricc-water evacuations. The enlargement of the intestinal glands is very remarkable; sometimes, but not always, Brunner's duodenal glands, generally Peyer's glands of the ileum, and most constantly and universally the solitary glands are enlarged. Peyer's patches are sometimes enormously swollen, and as large as in typhoid ferer, though without the deposit of the latter; but this is not elwaye the case. The colitary glands an almays found enlarged, and seem like largo grains of and scattered throughout the intestine. The kidneys show no disease except congestion, and the urinary bladder is found to be contracted.

In the post mortem examination of those who have died during the consecutive fever, the characteristic appearance of the collapsed stage above mentioned no longer exists. The peculiar colour and feel of the intestines are gone, and the interior is found to contain bilious matter, though the glands may still be found large. The kidneys are generally affected, and in some cases have presented much the appearance of these organs after scarlatina, or as they are found in those dying from very recent scarlatinal dropsy. They are large and congested, weighing, instead of nine ounces (the average weight of these organs), fifteen or sixteen ounces. The microscope shows the tubes to be gorged with a granular secreted matter; and very probably their pathological condition is similar to that of the scarlatinal kidney.

In the case of a woman who died in the sixth month of pregnancy, the liquor amnii was found to be in the usual abundance.

It will be seen that I have given my general experience of the disease and its treatment, and have made no mention of numbers. I have purposely done so, as I believe all the great errors into which we have lately fallen with respect to the various plans of cure have been due to this very fallacious manner of arraying figures and facts. A dozen cases of cholera are found, put against another dozen for comparison of treatment, when the disease in the two instances has been of a very different character; and what is worse, the cases of one practitioner are compared with those of another, on the assumption that the disease of the two is alike, and that the medical men are equally good observers. I have seen now more than one instance of a medical man vaunting his method of cure, and showing a long list of cases, where there could be no doubt that they were only examples of a milder form of cholera or severe diarrhœe; and such cases being compared with a like number of collapsed patients, the result was evident. I am sorry to say that I have known such cases fraudulently classed with well-established cholera; and thus a superiority of treatment has been given to the author of this act of dishonesty, while his more conscientious neighbour has entered his returns justly, and has had to bear invidious comparisons, alike galling to his feelings and injurious to his pocket.

I may state, that my experience -has been drawn during the late epidemic, from an obscrvation of about two hundred cases of cholera, the majority of which were examples of the very worst forms of the disease. This number is exclusive of a host of cases of choleraic and crdinary diarrhcea.

I cannot conclude without expressing my lament for the deplorable exhibition of weakness which we as a profession have shown during this time of trial. Instead of being a scientific body, as we were supposed to be, every oue has been jumping at conclusions, and forming his a priori modes of treatment, as though Bacon had never lived. It is to be hoped that, when the epidemic has passed, men will return to reason, and sit down and reconsider the opinions they have launched so hastily upon the world. I am not thinking of Dr. George Johnson, for I consider that gentleman rather hardly used. He had a perfect right to try any remedy he thought best, and to publish in the medical journals his account of the results which he obtained. It was his misfortune that the treatment which he adopted should have been so in accordance with the opinions of a homcopathic public press, that his report should have been alone selected from among many others, and paraded before the world.

17 St. Thomas Stroet, Southwart, Oct. 11th, 1854. 